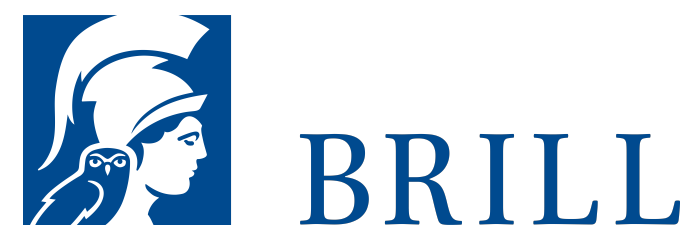

\title{
Kritik der neomythischen Vernunft
}

Band 1: Menschen als Götter der Erde. 180o-1945

Author: Linus Hauser

Zwei Drittel aller Westeuropäer halten sich für religiös. Aber diese Religiosität ist mehrheitlich nicht mehr die christliche. Der theistische Gottesbegriff, der Gott als eine den Menschen individuell ansprechende Person fasst, hat seine Akzeptanz eingebüßt. Neue Glaubensinhalte, Bruchstücke für neue Weltbilder werden sichtbar - Reinkarnationsglaube, Evolutionismus, Dänikens Präastronautik und Parapsychologie seien hier nur als Beispiel genannt. Es sind "religionsförmige Neomythen", die die Weltbilder der Moderne kennzeichnen. Sie werden in diesem großangelegten Werk einer umfassenden Gesamtschau unterzogen. Der erste Band behandelt den Neomythos von seinen Anfängen in der Aufklärung und während des Aufstiegs der wissenschaftsfundierten Technik bis hin zu den neomythischen Gedankenspielen der Nationalsozialisten. Hauser nimmt dabei die gesamte Kulturund Geistesgeschichte des ausgehenden 18., des 19. und der ersten Hälfte des 20. Jahrhunderts in den Blick (Stichworte u.a.: Mesmerismus, Spiritismus, Populärdarwinismus, Blavatskys Theosophie, katastrophisch ausgerichtete Kosmologien, völkische Phantastik, Ariosophie). Spätestens die Nationalsozialisten sind ein Fanal dafür, dass es einen Neomythos gibt, der das Humanum global zu gefährden vermag.

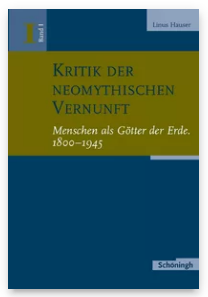

Published: o1 Jan 2004 Pages: 513 Seiten

Subjects: General, Theology and World Christianity Publisher: Brill | Schöningh

\section{Series:}

Kritik der neomythischen Vernunft, Volume: 1

E-Book (PDF) ISBN: 978-3657-77602-3 Price:

[US.:. \$162.00

Hardback ISBN: 978-3506-77602-о Price:

[USS] \$162.00 
Please send your order to: Brockhaus/Commission Tel: +49(o)71 541327 9216 | E-Mail: brill@ $\underline{\text { brocom.de }}$

For questions please contact: Brill Deutschland GmbH

Wollmarktstraße 115 | 33098 Paderborn | Germany

Tel: +49 (o)5251 69975 o | E-Mail: sales@brill.com. 